\title{
Critical Success Factors for Knowledge Transfer via Government Websites
}

\author{
Nurdiana Azizan ${ }^{1}$, Ross Smith ${ }^{2}$ and Vanessa Cooper ${ }^{2}$ \\ ${ }^{1}$ Faculty of Science and Technology, Islamic Science University of Malaysia (USIM), Nilai, Malaysia \\ ${ }^{2}$ School of Business IT and Logistics, RMIT University, Melbourne, Australia
}

\begin{abstract}
The transfer of knowledge pertaining to government is central to the success of e-government websites. The purpose of this paper is to investigate how Australian government website providers perceive critical success factors (CSFs) for the transfer of knowledge from government to users (citizens, business entities, employees and other government agencies) via an Australian government education website. CSFs are defined as "the limited number of areas in which results, if satisfactory, will ensure successful competitive performance for the organization" (Rockart 1979, p. 5) and knowledge transfer (KT) is defined as a process that includes "any exchange of knowledge between or among individuals, teams, groups or organizations" (King 2006, p. 538). It is the process by which knowledge is transmitted to, and absorbed by, users. Knowledge in this research is scoped to include government knowledge resources (information and services) made explicit and available to users via government websites. The research is exploratory, applying content analysis to analyse qualitative data that were collected using interview and focus group techniques. Szulanski's knowledge transfer (KT) four stages model was adapted as a lens to study CSFs. Eleven CSFs are identified, grouped into six themes, and associated with the four KT stages. The research provides guidance to practitioners, arguing that identifying and understanding the CSFs can support government website providers in taking decisions related to the internal operation of their website's content development and delivery activities, thus enhancing their capacity to deliver requisite knowledge to website users.
\end{abstract}

Keywords: E-government, Australia, Critical success factors, Knowledge transfer.

\section{Introduction}

Electronic Government (E-government) addresses the means by which contemporary governments around the world provide knowledge resources (information and services) to users, specifically citizens, businesses and other government agencies. Whilst such provision can proceed by various electronic channels, e-government is scoped for the purpose of this research as the utilisation of the Internet, particularly via websites, to improve and enhance government operations (Benefit view), to disseminate government information and services (Service view), to acquire knowledge through the website (Objective view), and to establish relationships between governments and their stakeholders, particularly citizens, employees, business sectors and government agencies (Relational view) (Azizan et al 2011).

The website has become the preferred channel for users seeking to access government information and services, especially in the case of knowledge-based websites (Ford \& Murphy 2008).

Copyright (C) 2011 Nurdiana Azizan, Ross Smith and Vanessa Cooper. This is an open access article distributed under the Creative Commons Attribution License unported 3.0, which permits unrestricted use, distribution, and reproduction in any medium, provided that original work is properly cited. Contact author: Nurdiana Azizan.E-mail: nurdiana@usim.edu.my 
Nevertheless, the website provides challenges to government - not merely to mount a website able to deliver information and services, but to ensure that the website delivers in a form that addresses user needs and facilitates the transfer of requisite knowledge. A substantial body of egovernment research focuses on the importance of information and communication technology (ICT), in particular the role of the website, in transforming relations between a government and its citizens. There is, however, little focus on knowledge management (KM) especially on knowledge transfer (KT).

Knowledge as defined and scoped for this research includes government knowledge resources (information and services) made explicit and available for users via a government website (Azizan et al 2011). The management of knowledge is increasingly important to government in order to face the challenges of the knowledge economy and vital for effective KT (Santinha \& de Castro 2010). KT is defined for this research as a process that includes "any exchange of knowledge between or among individuals, teams, groups, or organisations" (King 2006, p. 538).

Kuhn and Abecker (1997) assert that a failure to consider the elements of KT can result in costs arising from spending excessive time searching for knowledge and costs associated with errors arising from actions built upon inappropriate knowledge resources. Similarly, Traunmuller and Orthofer (2007) assert that attention to KT can support building better e-government solutions. It should also be noted that a government website must meet the knowledge resource (information and services) needs of both internal government users and those external to government (Sagheb-Tehrani 2010).

In light of the above, this paper addresses the following question:
What are the critical success factors (CSFs) for knowledge transfer (KT) via an Australian government education website, as perceived by the website provider?

In this study CSFs are defined as "the limited number of areas in which results, if they are satisfactory, will ensure successful competitive performance for the organisation" (Rockart 1979, p. 5). It has been recognised that there are generally a small number of such attributes that if performed well will create opportunity for success (King 2001).

In undertaking this study, a conscious decision has been taken to focus on the insights of the website provider. Government website providers have substantial established processes and infrastructure in place to assess user responses to the websites that they provide. That said, future studies could seek additional validation of the CSFs by seeking direct recourse to external website users.

In this paper, we present findings from an interpretive case study of a government agency in Australia ("AUSED" a pseudonym). This research has explored CSFs for the transfer of knowledge from Government to users (citizens, business entities, other government agencies and employees) via an Australian government education website, from the perspective of the Government website provider. A Ministry/Department of Education was selected, as education constitutes one of the most vital and widely used of the e- government services (United Nations 2008), and as such was deemed to provide a good initial candidate for the study of CSFs for KT via e-government websites.

The structure of this paper is as follows: the following sections briefly review the relevant literature, including the generation of a list of some potential CSFs for KT via a government website; the subsequent section discusses the research methods used; the penultimate sections report and discuss the key findings; followed by a short conclusion that explores the significance of the results. 


\section{Background - E-Government in Australia}

The Australian Government launched its egovernment agenda in March 2006 entitled the '2006 e-Government Strategy, Responsive Government: A New Service Agenda', seeking to provide better government services delivery (Australian Government 2006). This agenda is a development of an initial e-government strategy launched in 2002, 'Better Services, Better Government', which involved plans for the integrated and comprehensive use of new technologies for government information, service delivery and administration (Australian Government 2006). The 2006 service agenda concentrates on four primary areas: meeting users' needs, establishing connected service delivery, achieving value for money, and enhancing public sector capability (The Australian Government Information Management Office (AGIMO) 2008). As a partial endorsement of the strategies advocated, as revealed in the report 'Interacting with Government: Australians' use and satisfaction with egovernment services', in 2009 Australians used the internet to interact with government more than any other method (see AGIMO 2008).

To operationalise strategies, the Australian Federal Government supports each state implementing its own e-government agenda. In Victoria, where this research has been conducted, the agenda has evolved in stages according to the government's perceived needs of citizens. For example, the government has sought to improve its Web Content Accessibility Guidelines in order to provide better services to those with disabilities (AGIMO 2008). The government has also concentrated on employing or training staff with appropriate skills, especially ICT skills, to implement its egovernment strategies (AGIMO 2008). With the emergence of Web 2.0, the Victorian Government is establishing a Government 2.0 Taskforce to investigate how it might best utilise Web 2.0 technologies to enhance the effectiveness and efficiency of service delivery, public administration and community engagement (AGIMO 2008).

\section{Knowledge - Definition}

The emerging challenges of the knowledge economy have promoted increasing government commitment to $\mathrm{KM}$, with $\mathrm{KM}$ now a priority on the policy agenda of many nations (Santinha \& de Castro 2010). Organisations that manage their knowledge effectively can improve their functioning in many dimensions.

Definitions of knowledge proliferate. For example, Polanyi (1962) and Nonaka (1991) classify knowledge as tacit (personal and hard to formalise) and explicit (formal and systematic) and argue the need to manage knowledge of both forms. Sternmark (2002), on the other hand, argues that all knowledge is tacit and that what can be made tangible is information. Knowledge has been conceptualised within a hierarchical structure, from data, seen as facts, becoming meaningful information as a result of the provision of context, then becoming knowledge when interpreted, and applied in context (Sternmark 2002).

Drawing upon the above, for the purposes of this research, knowledge is defined and scoped to include government knowledge resources (information and services), made explicit and available for users via a government website, which becomes meaningful to website users when they interpret and apply it in context.

\section{Szulanski's KT Model}

This research seeks to view CSFs through the lens of KT. An adapted form of Szulanski's (2000) intra-organisational KT model has been employed to facilitate identification of CSFs for KT via a government website (Cooper and Lichtenstein 2010). This model has been chosen because it is widely recognised and supported through application over many studies. It should be appreciated, however, that Szulanski's original KT model is designed to describe internal KT (i.e. within an organisation). Cooper et al (2006), however, have adapted the model to studies of CSFs for external KT 
in Business-to-Business (B2B) contexts. This research has extended application of Szulanski's KT model to identify CSFs for internal and external KT in an e-government context.

Szulanski's (2000) intra-organisational KT model consists of four stages, namely initiation, implementation, ramp-up and integration. The initiation stage begins when the website user has recognised a need for knowledge and starts a search for knowledge to fulfil that need. Once the need for that knowledge is identified, the feasibility of transferring that knowledge is explored. The implementation stage begins when knowledge resources flow between the source and the recipient. The implementation related activities conclude after the recipient begins using the transferred knowledge. The ramp-up stage begins when the recipient starts using the received knowledge. During this stage, the recipient will be concerned with identifying and resolving unexpected problems that arise while using the new knowledge. Finally, the integration stage begins after the recipient achieves satisfactory results with the transferred knowledge. The use of the transferred knowledge becomes routinised. Integration is complete when old knowledge is replaced by new knowledge or practices.

\section{Potential CSFs for KT via Government Websites}

A conceptual framework underpinning this research has been derived from a substantial literature review, to seed the identification of CSFs from the rich data set collected in this study (Azizan 2011). A focus of the literature review has been on CSFs and concepts raised in a number of relevant associated literatures, including: KM; customer service (CS) and Web-based Self Service (WSS). The conceptual framework is presented in Table 1 , cast in terms of 6 groupings, and some associated concepts, with reference to the relevant literatures. This conceptual framework has been used to:

(1) Seed the analysis of the interviews and focus groups data; and

(2) As a basis for comparing and aligning the final set of validated CSFs with the extant literature. 
Table 1: Some Potential CSFs for KT via a Government Website (KM: Knowledge Management; CS: Customer Service; WSS: Web-based Self-Service)

\begin{tabular}{|c|c|c|}
\hline Potential Groupings & Description & Associated Concepts \& \\
\hline \& CSFs & & Authors \\
\hline 1: Management & The productivity of an organisation depends on the & (KM: King, Marks \& \\
\hline Leadership & management of valid knowledge through the & McCoy 2002; CS: Pan \& \\
\hline Top Management & exercise of various forms/styles of leadership. & Lee 2003; WSS: Cooper, \\
\hline \multirow[t]{2}{*}{ Support } & & Lichtenstein \& Smith \\
\hline & & 2006) \\
\hline 2: Website Users & The provider needs to aware of the knowledge & (WSS: Cooper, \\
\hline User's knowledge & resources that are critical to users. & Lichtenstein \& Smith \\
\hline \multirow[t]{3}{*}{ needs } & & 2006; CS: Liu \& Lee \\
\hline & & 2006; KM: Phusavat \& \\
\hline & & Anussomnitisarn 2008) \\
\hline User's level of ICT & Management must be aware of the ICT literacy & (WSS: Cooper, \\
\hline \multirow[t]{3}{*}{ lieracy } & levels needed to use WSS. ICT literacy is a driver of & Lichtenstein \& Smith \\
\hline & CRM. & 2006; CS/KM: Liu \& Lee \\
\hline & & 2006) \\
\hline User's need for & Knowledge sharing among employees is an & (KM: Misra, Hariharan \& \\
\hline training and & important element in an electronic KM framework & Khaneja 2003; WSS: \\
\hline \multirow[t]{3}{*}{ education } & for organisations. The provider should provide & Cooper, Lichtenstein \& \\
\hline & professional training and education to employees, & Smith 2006; CS: Liu \& \\
\hline & and as sistance to users of a WSS system. & Lee 2006) \\
\hline User's perceptions & An appreciation of usability must include how a & $(\mathrm{KM} / \mathrm{CS}:$ Barnes \& \\
\hline \multirow[t]{3}{*}{ of usability } & user perceives and interacts with a website, and & Vidgen 2006; WSS: \\
\hline & navigates and searches. Creating a positive & Cooper, Lichtenstein \& \\
\hline & experience for users is important. & Smith 2006) \\
\hline User's need to have & Users need to receive notification services from the & (KM: Misra, Harihan \& \\
\hline website awareness & website for any updates. They should show & Khaneja 2003; CS: \\
\hline and to receive & initiative, to be aware of organisational knowledge & Barnes \& Vidgen 2006; \\
\hline \multirow[t]{4}{*}{ update notification } & and be willing to institutionalise it. The provider on & WSS: Cooper, \\
\hline & the other hand, needs to establish awareness and & Lichtenstein \& Smith \\
\hline & market programmes in order to promote WSS to & 2006) \\
\hline & users. & \\
\hline 3: Develop & Human resource division should match work & (WSS: Cooper, \\
\hline Employees & participant qualifications with the requirements of & Lichtenstein \& Smith \\
\hline Required match of & work tasks for smooth process execution. & 2006; KM: Staniszlcis \& \\
\hline employee roles and & Additionally, management should provide training & Staniszkis 2006; CS: \\
\hline competencies & to support agents in order to promote KT and reuse. & Siddiquee 2008) \\
\hline 4: Content/ & The provider must ensure that required knowledge & (KM: Misra, Harihan \& \\
\hline Presentation & resources are available to the users, whenever & Khaneja 2003; CS: \\
\hline Required knowledge & and wherever they want. & Arendsen \& Engers \\
\hline \multirow[t]{3}{*}{ content } & & 2004; WSS: Cooper; \\
\hline & & Lichtenstein \& Smith \\
\hline & & 2006) \\
\hline Appropriate & Knowledge presented through the web interface & (WSS: Cooper, \\
\hline knowledge & must be readily accessible. A website with an & Lichtenstein \& Smith \\
\hline \multirow[t]{2}{*}{ presentation } & attractive, simple design can facilitate access. & 2006; KM/CS: Millard \\
\hline & & 2006) \\
\hline 5: Technology & To ensure that knowledge resources are available to & (KM: Misra, Harihan \& \\
\hline \multirow[t]{4}{*}{ ICT infrastructure } & users, the website provider requires an appreciation & Khaneja 2003; WSS: \\
\hline & of appropriate supporting ICT infrastructure. & Cooper, Lichtenstein \& \\
\hline & & Smith 2006; CS: Liu \& \\
\hline & & Lee 2006) \\
\hline
\end{tabular}




\begin{tabular}{|c|c|c|}
\hline Interactive platform & Knowledge presented through the web interface & (KM/WSS: Misra, \\
\hline \multirow[t]{4}{*}{ functionality } & must be readily accessible to users, with & Hariharan \& Khaneja \\
\hline & functionality that facilitates access. Users are also & 2003; CS: Liu \& Lee 2006) \\
\hline & encouraged to participate by giving feedback & \\
\hline & regarding the website. & \\
\hline Search engine & Knowledge assets should be stored in an electronic & (KM/CS: Misra, Harihan \\
\hline \multirow[t]{4}{*}{ functionality } & medium to enable efficient access and retrieval. The & \& Khaneja 2003; WSS: \\
\hline & provider must ensure that website navigation is & Piccoli et al. 2004) \\
\hline & functioning in order for users to access intended & \\
\hline & knowledge. & \\
\hline \multirow[t]{3}{*}{ Security requirements } & The provider must seek to ensure system security & (WSS: Cooper, \\
\hline & and data privacy. & Lichtenstein \& Smith \\
\hline & & 2006; CS/KM: Smith 2008) \\
\hline 6: Organisational & The government provider must engender an & (KM/WSS: Misra, \\
\hline Culture & environment where teamwork is embraced, to scan & Hariharan \& Khaneja \\
\hline Positive user attitude & the environment for potential opportunities and & 2003; CS: Liu \& Lee 2006) \\
\hline to the technology and & threats in order that the organisation is prepared to & \\
\hline Change management & exploit the situation to its advantage, administer and & \\
\hline \multirow[t]{2}{*}{ support processes } & maintain the KM portal and its contents so that it is & \\
\hline & geared to meet the demands of users. & \\
\hline
\end{tabular}

\section{Research Methodology}

The research has employed an interpretive case study approach, applying qualitative data capture and analysis methods. The case study research method enables examination and scrutiny of the rich organisational situation and supports the use of multiple data capture and analysis techniques so facilitating the triangulation of analysis outcomes (Cooper and Lichtenstein 2010).

The case study was conducted at one government agency in Australia "AUSED". AUSED is an education-based organisation, chosen because this sector provides a rich environment in which to investigate CSFs for KT via government websites. United Nations (2008) argues that the education sector provides fertile ground for the provision of government services.

In this research, an adapted form of Rockart's CSF method was adopted for data collection, including an introductory workshop, interviews and a focus group. In the introductory workshop the contact official was briefed on the purpose of the study and the research process. Following the workshop, semi-structured interviews with nine respondents were conducted. The respondents were selected from the staff involved in the development and management of the Australian government website, including top, middle and operational management level appointments across the organisation. The respondents were requested to identify the CSFs for KT via the government website, at each stage of the KT process (Initiation, Implementation, Ramp-up and Integration). The interview transcripts were then analysed, using inductive qualitative content analysis techniques (Creswell 2009). The potential CSFs (see Table 1) were available to seed this analysis, supplemented with the outcomes of the qualitative analysis which allowed the researchers to code category names that emerged from the data (Hsieh \& Shannon 2005). Subsequently, a focus group was conducted, involving the same respondents as in the interviews. The purpose of the focus group was to validate the CSFs resulting from the interviews. In this session, the list of the CSFs from the interviews was tabled. Respondents then shared each others' experiences and a confirmed list of CSFs was generated. 


\section{Results - Critical Success Factors (CSFs)}

Drawing upon analysis of the interviews, respondents identified $11 \mathrm{CSFs}$ for KT via the Australian government education website (see Table 2). Subsequent reflection on these, suggested themes that could be mapped against four of the six groupings identified in the conceptual framework (Table 1) (i.e. management role, user focus, content focus, and technology focus). The absence of CSFs related to the themes employee focus and organisational culture was explored in the focus group setting, and was identified as a consequence of a drive to implement egovernment initiatives widely, across the broad sweep of Australian government agencies with each state preparing guidelines for government agencies to follow. Victorian government guidelines (Victoria State Government 2010) focus heavily on service delivery to citizens, reflected in these results in the number of identified CSFs related to user, content and technology focus (in fact ten of the 11 CSFs reported in Table 2 are classified in these theme areas). As such, employee focus imperatives and organisational culture imperatives were not seen as critical. This is not to say that such matters were not seen as necessary to the achievement of KT by the respondents instead they were seen as established practice that underpinned all public service undertakings but not specifically critical to the achievement of KT in this context. As an aside, this distinction was not observed in a CSF study of an education agency in Malaysia, as recently reported (Azizan et al 2011), where factors related to both these themes were classified as critical in this context. The CSFs identified are listed and defined in Table 2. 
Table 2: CSFs for KT via the Australian Government Education Website

\section{CSF AUSED}

Theme 1: Management role

AUS_CSF 11 - Governance

Senior management must accept and exercise overall website governance responsibilities. Of particular importance, management must exercise control over the capabilities of, and interactions between, the multiple tools that are provided to users via the website. This includes, in particular, taking key decisions concerning which tools are available to the public and those which are restricted to users who are internal to the organisation.

Theme 2: User focus

AUS_CSF 1 - Awareness and notification

Promotion of the website and proactive communication should be undertaken to raise awareness and to inform current and potential external users of the website regarding its content, functionality, modifications and new developments.

\section{AUS_CSF 2 - Usability: Functionality and navigation}

The website should be developed to provide users with easy-to-use functionality that will support them with clear and unambiguous advice concerning their current location and navigation path options. Different categories of users should be supported when locating and retrieving required knowledge efficiently and effectively.

AUS_CSF 3-User focus: Understand needs of recipient

The website should provide relevant knowledge to users in such a way that the content is easy to understand, and is written in simple and meaningful language chosen with the recipient in mind.

AUS_CSF $4-$ Presentation of knowledge

Website content should be presented with the recipient in mind. The content format should be concise, attractive, informative and available in multiple formats that take advantage of the variety of available presentation options, including colour, font and the opportunity to include multimedia. The formats need also to consider the size of the document.

AUS_CSF 8-User positive experience

The website should be viewed as a positive experience by users, by providing knowledge according to users' requirements.

Theme 3: Employee focus

This area was not raised by participants

Theme 4: Content focus

AUS_CSF 5-Content

The website should contain content that is regularly updated, accurate, meets user requirements and includes the date of last update.

AUS_CSF 9 - Knowledge storage and retrieval: Architecture

Guidelines should exist that authors should follow when preparing content and procedures to ensure compliance. The guidelines include site maps that specify locations for the storage of knowledge.

Theme 5: Technology focus

AUS_CSF 6-Accessibility

The website should be available, whenever it is needed, and provide alternative ways for users to access

knowledge that is fast and easy for users to download.

AUS_CSF 7 - ICT infrastructure: Awareness of users' technology availability

Users' technology availability must be considered in order to decide how to prepare the content and present knowledge.

AUS_CSF 10 - Search engine

The website should provide users with efficient and effective search functionality, including search engine capabilities.

Theme 6: Organisational culture

This area was not raised by participants 


\section{The Association of CSFs with KT Stages}

In this section we unpack the 11 CSFs reported, highlighting, in particular, instances where a CSF was the firstmentioned by a respondent when considering each KT stage. It should be noted that when discussing each KT stage, respondents tended to mention many factors. The subset of first-mentioned CSFs at each stage provides some insight into which CSFs were at the front of each respondent's mind. The use of the first-mentioned response in this way has been previously used by researchers to capture what is seen as most important to study respondents (e.g. Krause \& Jay 1994).

Some observations, drawn from these results, include:

1) CSFs have been identified almost uniformly across the four stages: eight CSFs during the Initiation stage, seven in the Implementation and Integration stages, and five during the Ramp-up stage. This indicates that the respondents have no difficulty in appreciating critical factors across all stages of the KT model.

2) Overall, the most frequently cited CSFs are: CSF 3 - User Focus: Understanding the needs of the recipient; CSF 2 Usability: Functionality and navigation; and CSF 5 - Content. AUSED acknowledges that in order to successfully transfer knowledge to users, the government provider must be responsive to users' needs.

3) If one focuses at each stage on the firstmentioned CSF, the most important CSFs for the achievement of each KT stage are:

- Initiation: CSF 2 - Usability: Functionality and navigation;

- Implementation: CSF 6 - Accessibility;

- Ramp-up: CSF 3 - User Focus: Understanding the needs of the recipient; and
The above highlights that at Initiation, which involves the knowledge provider preparing knowledge content for the website and the potential user recognising a need for knowledge and commencing a search for that knowledge, the respondents see as most critical that easy-to-use functionality that will support users with clear and unambiguous advice must be identified (CSF 2 - Usability: Functionality and navigation). At Implementation which begins with the decision of the knowledge recipient to proceed to acquire the knowledge, focus shifts to the ICT infrastructure which must support a website that is available, whenever it is needed, and must provide alternative ways for users to access knowledge that is fast and easy for users to download (CSF 6 Accessibility). At Ramp-up, which begins when the knowledge recipient starts applying the received knowledge, the respondents see as critical that the website should provide relevant knowledge to users in such a way that the content is easy to understand, and is written in simple and meaningful language chosen with the recipient in mind (CSF 3 - User Focus: Understand needs of recipient). Finally, at Integration, when the knowledge recipient has received the transferred knowledge and moves to integrate its use with their needs, the respondents see that it is critical that the website should contain content that is accurate, relevant, regularly updated and which meets user requirements (CSF 5 Content). At this stage the content itself is seen as critical - a lack of accuracy, relevance, currency and a failure to meet user requirements, will be exposed as the user seeks to integrate the acquired knowledge with their ongoing needs.

\section{Conclusion}

In this paper results have been reported for an analysis of CSFs for KT from government sources to internal and external stakeholders, via a government education website operated by the Australian government. The analysis has drawn upon

- Integration: CSF 5 - Content. 
interviews with key Australian government respondents.

It is recognised that this study, built upon a single case study of an educational agency of the Australian government, may not necessarily be applicable to other contexts (i.e. educational agencies of other national governments and/or other forms of government agency). Ongoing studies of educational agencies of other national governments are in progress, to gain insight into the extent to which the CSFs reported are shared in different national government contexts. The paper argues that this study has produced a fully researched set of CSFs for KT via a government education website, from a government provider perspective, that may be considered and possibly tailored to other areas of government activity. Furthermore, identifying and understanding the CSFs has the capacity to provide practical guidance to practitioners, allowing them to identify and understand the CSFs and their impact on the various stages of KT, so facilitating government website providers in taking decisions related to the internal operation of their website's content development and delivery activities, and thus to enhance their capacity to deliver requisite knowledge to website users. It must be understood, however, that the CSFs proposed are considered by the study respondents to be necessary for success, but that they should not necessarily be considered sufficient for success.

\section{References}

Arendsen, R. \& van Engers, T. M. (2004). "Reduction of the Administrative Burden: An E-Government Perspective," paper presented to Electronic Government, Berlin, 2004.

Australian Government (2006). "Responsive Government a New Service Agenda: 2006 EGovernment Strategy," pp. 1-44, viewed 27 October2007,

<http://www.finance.gov.au/publications/20 06-e-government-strategy/docs/e gov_strategy.pdf>.
Azizan, N. (2011). 'Critical Success Factors for Knowledge Transfer via Australian and Malaysian Government Education Websites: A Comparative Case Study,' Doctoral Thesis, RMIT University, Australia.

Azizan, N., Smith, R. \& Cooper, V. (2011). 'Critical Success Factors for Knowledge Transfer via Malaysian Government Website,' paper presented to 1st Exploring Leadership and Learning Theories inAsia (ELLTA) Conference, Universiti Sains Malaysia, Penang, Malaysia, 15-17 February.

Barnes, S. J. \& Vidgen, R. T. (2006). "Data Triangulation and Web Quality Metrics: A Case Study in E-Government," Information \& Management, 43 (6), 767-77.

Cooper, V. A. (2009). "A Review of the Critical Success Factor Method Using Insights from an Interpretivecase Study," Journal of Information Technology Case Research, 11 (3), 9-42.

Cooper, V. A. \& Lichtenstein, S. (2010). "Supporting knowledge transfer in web-based managed IT Support," Journal of Systems and Information Technology, 12 (2), 140-60.

Cooper, V., Lichtenstein, S. \& Smith, R. (2006). "Knowledge Transfer in Enterprise Information Technology Support Using WebBased Self-Service Systems," International Journal Technology Marketing, 1 (2), 145-70.

Creswell, J. W. (2009). 'Research Design: Qualitative, Quantitative, and Mixed Methods Approaches,' 3rdedn, Sage, London.

Ford, N. \& Murphy, G. (2008). "Evaluating the Potential of a Web-Based Portal to Support the Leverage of Professional Expertise Across Local Authority Boundaries," Local Government Studies, 34 (3), 397-418.

Hsieh, H.-F. \& Shannon, S. E. (2005). "Three Approaches to Qualitative Content Analysis," Qualitative Health Research, 15 (9), 1277-88, viewed 2 June 2008, <http://qhr.sagepub.com/cgi/reprint/15/9/ 1277>. 
11 Journal of e-Government Studies and Best Practices

King, W. R. (2001). "Developing a Sourcing Strategy for IS: A Behavioral Decision Process and Framework," IEEE Transactions on Engineering Management, 48 (1), 15-24.

King, W. R. (2006). 'Knowledge Transfer,' Idea Group Inc., 2006.

King, W. R., Marks, P. V. \& McCoy, S. (2002). "The Most Important Issues in Knowledge Management," Communications of the ACM, 45 (9), 93-7.

Krause, N. M. \& Jay, G. M. (1994). "What Do Global Self-Rated Health Items Measure?," Medical Care, 32 (9), 930-42.

Kuhn, O. \& Abecker, A. (1997). "Corporate Memories for Knowledge Management in Industrial Practice: Prospects and Challenges," Journal of Universal Computer Science, 3 (8), 929-54.

Liu, H-y. \& Lee, T-y. (2006). "Customer Relationship Management Drivers for EGovernment in Taiwan," paper presented to 7 th International Conference of the Faculty of Management Koper, Portoroz, Slovenia,23-25 November 2006, <http://www.fmkp.si/zalozba/ISBN/961-6573-160/papers/MIC6331.pdf>.

Millard, J. (2006). 'Knowledge Transfer and Innovation Strategies in E-Government,' in T Roland (ed.), Knowledge transfer for egovernment, Trauner Verlag, Linz, Austria; 20, 49-65.

Misra, D. C., Hariharan, R. \& Khaneja, M. (2003). "E-knowledge Management Framework for Government Organizations," Information Systems Management, 20 (2), 3848.

Nonaka, I. (1991). 'The Knowledge-Creating Company,' Harvard Business Review, 69 (6), 96-104.

Pan, S. L. \& Lee, J.-N. (2003). "Using e-CRM for a Unified View of the Customer," Communications of the ACM, 46 (4), 95-9.
Phusavat, K., Anussornnitisarn, P., Devahastin-Suthapreda, V., Kuljittiprasit, P. \& Thamsatitdej, P. (2008). "Service Satisfaction Through External Knowledge Management," International Journal Services and Standards, 4 (2), 182-93.

Piccoli, G., Brohman, M. K., Watson, R. T. \& Parasuraman, A. (2004). "Net-based Customer Service Systems: Evolution and Revolution in Web Site Functionalities," Decision Sciences, 35 (3), 423-55.

Polanyi, M. (1962). “Tacit Knowing: It's Bearing on Some Problems of Philosophy," Reviews of Modern Physics, 34 (4), 601-16.

Rockart, J. F. (1979). "Chief Executives Define Their Own Data Needs," Harvard Business Review, 57 (2), 81-93.

Sagheb-Tehrani, M. (2010). "A Model of Successful Factors towards E-Government Implementation," Electronic Government, an International Journal, 7 (1), 60-74.

Santinha, G. \& de Castro, E. A. (2010). "Creating more Intelligent Cities: The Role of ICT in Promoting Territorial Governance," Journal of Urban Technology, 17 (2), 77-98.

Siddiquee, N. A. (2008). "E-government and Innovations in Service Delivery: The Malaysian Experience," International Journal of Public Administration, 31, 797-815.

Smith, A. D. (2008). "Exploring National Identification Programs among Web-Enabled Professionals," Industrial Management \& Data Systems, 108 (4), 455-77.

Staniszkis, W. \& Staniszkis, E. (2006). Administrative Process Management: Setting the Scene, in R. Traunmuller (ed.), Knowledge transfer for e-government: Seeking better e-government solutions, Trauner Verlag, Linz, Austria; 20, 117-132.

Sternmark, D. (2002). "Information Vs Knowledge: The Role of Intranets in Knowledge Management," paper presented to 
35th Hawaii International Conference on System Sciences, Hawaii, 2002, <http://www2.computer.org/portal/web/csd l/doi/10.1109/HICSS.2002.994043>.

Szulanski, G. (2000). "The Process of Knowledge Transfer: A Diachronic Analysis of Stickiness," Organizational Behavior and Human Decision Processes, 82 (1), 9-27.

The Australian Government Information Management Office (AGIMO) (2008). Department of Finance and Deregulation: Australian Government Information Management Office, viewed 16 June 2010, <http://www.finance.gov.au/agimo/index.ht $\mathrm{ml}>$.

Traunmuller, R. \& Orthofer, G. (2007). "Knowledge Transfer in E-Government," pp. 17, viewed 16February 2009, <http://unpan1.un.org/intradoc/groups/publ ic/documents/unpan/unpan026015.pdf>.

United Nations (2008). "UN E-Government Survey 2008: From E-Government to Connected Governance," Economic \& Social Affairs, p. 246, viewed 2008, via United Nations Online Network in PublicAdministration and Finance (UNPAN) (RMIT University) <http://www.unpan.org/egovkb/global_repo rts/08report.htm>.

Victoria State Government (2010). "eGovernment Resource Centre," Department of Innovation Industryand Regional Development, viewed 2 June 2010, $<$ http://www.egov.vic.gov.au/>. 